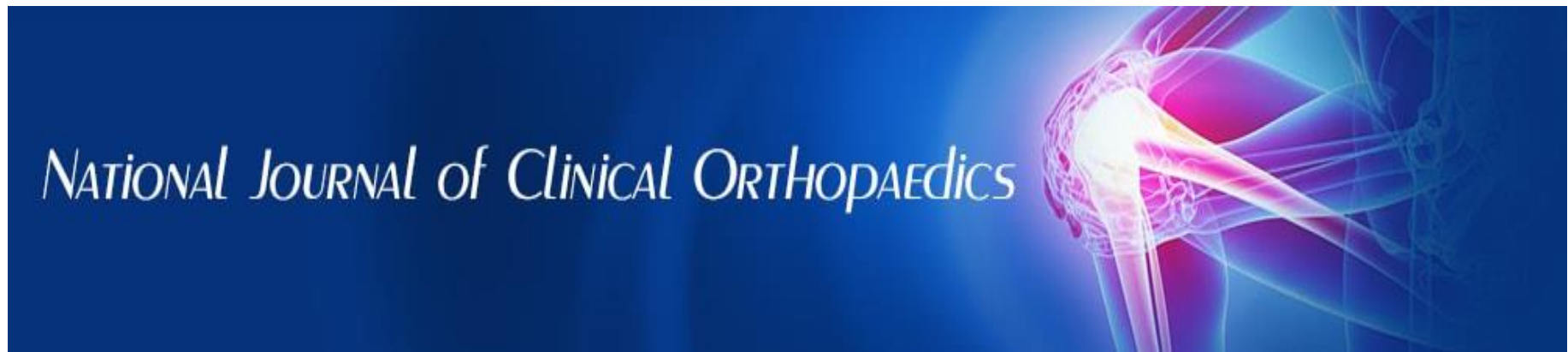

ISSN (P): 2521-3466

ISSN (E): 2521-3474

(C) Clinical Orthopaedics www.orthoresearchjournal.com 2021; 5(4): 31-36

Received: 13-05-2021

Accepted: 21-06-2021

Dr. Ahmad Shakir Turkey Alawadi

M.Sc. Diploma, Department of Orthopedic, AL-Karkh General Hospital, AL-Karkh Health Directorate, Baghdad, Iraq

Dr. Yaman Ahmad Kadhim M.B.CH.B, Department of Orthopedic, Arab Board, ALkarkh general Hospital, ALKarkh Health Directorate, Baghdad, Iraq

Dr. Hamed Gata Hassen

M.Sc. Department of Orthopedic, Baghdad, Iraq
Corresponding Author: Dr. Ahmad Shakir Turkey Alawadi

M.Sc. Diploma, Department of Orthopedic, AL-Karkh General Hospital, AL-Karkh Health

Directorate, Baghdad, Iraq

\section{Combined Cortico-cancellous and cancellous fresh paternal allograft in defect post resection of benign bone tumors of long bones in children, review of literatures with two cases study}

\section{Dr. Ahmad Shakir Turkey Alawadi, Dr. Yaman Ahmad Kadhim and Dr. Hamed Gata Hassen}

DOI: $\underline{\text { https://doi.org/10.33545/orthor.2021.v5.i4a.325 }}$

\section{Abstract}

We study the use of paternal fresh allograft in pediatric massive bony loss (post benign bone tumor resection) with a graft type of combined Cortico-cancellous and cancellous bone, with a good result of rapid and complete union with no recurrence with in 2years of follow up, with no any sign of local or systemic rejection. Study of 2 patients, one of an osteoblastoma in female of 9 years old in shaft femur and the second case was an aneurysmal bone cyst (ABC) in male of 11 years old in distal third of fibula where in both do enbloc resection for a big bony lesions in such young age group, the defect was $8 \mathrm{~cm}$ in the female and $9 \mathrm{~cm}$ in male case. We reconstruct these defects by the fresh non-frozen paternal allograft which still not widely used method and we add the use of Combined Cortico-cancellous and cancellous bone graft of iliac crest area which was not used or mentioned before in literatures and we do internal fixation in both and we wash the graft 2 times pre and post application in the gap with a normal saline for each case, follow up by monthly $\mathrm{x}$-ray films till healing. Was conclusive and more than expected regarding healing rate and union which was 6 month in female case and 5 month in male and no complication in such big bony graft mass. In Followed up of 2 years no recurrance was seen and both donors and recipients without any disability nor morbidity.

Keywords: Large bony defect in children, paternal fresh allograft and Combined Cortico-cancellous and cancellous graft type

\section{Introduction}

Two patients of big benign bone tumors in children. One of them was an osteoblastoma of shaft femur (female 9 years old) and the second case was aneurys mal bone cyst (ABC) of distal third fibula (boy 11 years old) both of them with large area of bony involvement. and decision of treatment was wide or enbloc resection of these bony lesions with the use for structural reconstruction, paternal fresh allograft to replace these bony defects in those children and here in our two cases we add the use of combined cortico- cancellous and cancellous bone graft of iliac crest area (fresh, non-frozen) as a new method not used before in literatures, which had the ability for enhancing rapid and good healing properties and also availability in good quantity.

\section{Osteoblastoma}

Uncommon benign bone tumors that accounts for about (1\%) of all benign primary bone tumors and $(3 \%)$ of all benign bone tumors ${ }^{[1,4]}$. adolescent and young adults are most often affected by osteoblastoma ${ }^{[1,2,3,4]}$ the tumors typically appear between the age of 10and 30 years old and are twice as common in males as in females ${ }^{[1,2,3,4,9]}$, occur most often in the lower vertebrae of the spine and sacrum or the long bones of lower extremity and feet, commonly affect the posterior elements of spine ${ }^{[1,3,4,9]}$, found within the Cortex, medullary cannal or periosteal tissue ${ }^{[1,4,6]}$. there is slight predominance of metaphysial over diaphyasial location, the size of osteoblastoma ranged between1_11 cm with mean of $3-2 \mathrm{~cm}^{[3,6,9]}$. 
Clinically are more often asymptomatic or present as a dull. Localized pain, swelling or painful scoliosis when involve the spine. Physical examination reveal swelling, muscle atrophy or limping and tender in palpation ${ }^{[1,2,4,9]}$.

\section{Diagnosis}

Plain radiography have a variable radiographic appearance ranging from indolent to very aggressive lesion ${ }^{[1,9]}$, it show radiolucent lesion $2 \mathrm{~cm}$ in size (nidus) surrounded by thin margin of reactive new bone formation that may have expanded $[3,8,9]$.

CT scan, MRI, Bone scan ${ }^{[1,2,3,4,8,9]}$.

Angiography ${ }^{[3,4]}$ staging tumor of the spine, biopsy ${ }^{[2,6]}$ to confirm diagnosis.

\section{Treatment}

Usually involve surgical operation to remove the tumor without damaging the surrounding structures, either enbloc resection or curettage and bone grafting with or without internal fixation $[1,2$, 4, 7] Enbloc resection is the preferred treatment $(1,3)$ when possible.

There is no definite role for adjuvant chemotherapy or radiotherapy $[1,2,3,7]$.

\section{Another treatment options include}

- Radiofrequency ablation with CT - guided

- Percutaneous image guided cryo therapy

- Magnetic resonance guided focused ultra sound for treating intra - articular osteoblastoma ${ }^{[7]}$.

\section{Prognoses}

Is generally excellent $\left[\begin{array}{ll}1, & 8\end{array}\right]$ reported recurrence rate of approximately $10-20 \%[1,2,5,6,9]$. There is a very rare risk of malignant transformation ${ }^{[1,2,3,4,5]}$.

\section{Aneurysmal bone cyst (ABC)}

Are rare benign bony lesions but locally aggressive most frequently occur in the first and second decade of life $[11,13,14,15$, $16,17,19]$, the true etiology is still unknown and may be vascular, traumatic or genetic $[11,13,14,16,17]$. Female are slightly more affected than male, (ABC) accounts for only (1-6\%) of all

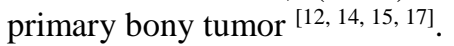

$\mathrm{ABC}$ has predilection for the metaphysis of the long bones including the femur, tibia, humerus, spine and pelvis, but $\mathrm{ABC}$ can also any other localization or site of entire skeleton [12, 14, 15, $16,19]$.

\section{Clinically}

Can cause pain, swelling and pathological fracture, neurological deficit if involve the spine, limping and limp length discrepancy if nearby growth plate area ${ }^{[12,14,16,19]}$.

$\mathrm{ABC}$ can be either primary or secondary; primary lesion that arise without evidence of another lesion $70 \%$ while secondary in the presence of another lesion(pre- existing bony lesion) $30 \%$, which add in the challenge of $\mathrm{ABC}$ diagnosis and treatment where it may confused with other lesion even after histopathology [12, 13, 14, 16, 17, 19].

\section{Diagnosis}

- Radiographically: Appear as expansile eccentric and lytic lesion with bony septae (bubbly appearance) $(12,19)$. M.R.I and CT scan ${ }^{[11,12,15,19] .}$

- Biopsy; the role of image guided needle biopsy prior to surgery is debated ${ }^{[13]}$.
- Cytogenetic technique is necessary to diagnose and differentiate primary from secondary one ${ }^{[14,15]}$.

\section{Treatment: options are many}

\section{A. Surgical Treatment}

- Aggressive curettage $(\bar{\mp})$ adjuvant and bone grafting are the standard option $[11,12,13,16,17,19]$.

- Enbloc resection as associated with lowest risk of recurrence but at the cost of high morbidity to the patient ${ }^{[12,}$ 14].

The adjuvant therapies are used to reduce recurrence (12) which include: high speed burr, hydrogen peroxide, organ beam. Phenol, cryo surgery and use of polymethylmethacrylate bone

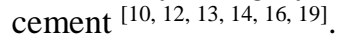

\section{B. Alternative Treatment modalities}

- Adjuvant radiotherapy but was in the past, arterial embolization pre-post-surgery or primarly, sclero therapy (ethi bloc), curopsy, percutaneous injection of (doxycycline, calcitonin or methylprednisolone). Systemic therapy by biphosphonate, denosumab or calcitonin ${ }^{[10,12,14]}$, also intra lesional injection of bone marrow ${ }^{[14]}$.

- Finally the best local control rate can be achieved by enbloc resection $[10,16,17]$, Treatment types are largerly based on personal experience and institutional preference ${ }^{[12,13]}$.

- Recurrence rate (local) up to $25 \%$ and more common in children with open physis and metaphysial lesion [16, 17, 18, 19] and male gender ${ }^{[14]}$.

- Most of recurrence occur during the first 2 years after Treatment ${ }^{[13]}$.

- Prognosis for $\mathrm{ABC}$ is generally excellent and over all cure rate $90-98 \%{ }^{[17]}$.

\section{Method and material}

This study was done in Al karkh general hospital in iraq, in orthopedic department, two patients where the first one was a female child of 9 years old presented with dull ache in right thigh not resolved by analgesia for more than one month and then develop limping, with examination reveal tenderness in mid-thigh area even mild muscle wasting, so survey done by plain $\mathrm{x}$ - ray, MRI and CT- scan.

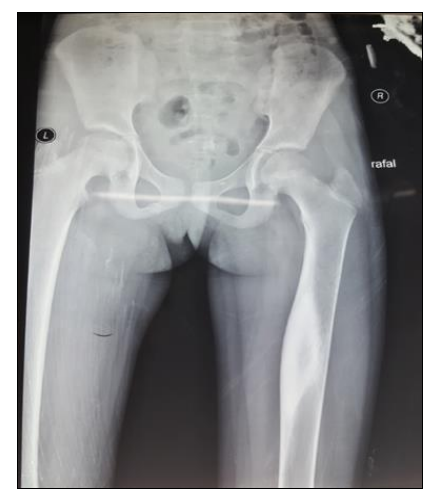

Fig 1: Female 9 years old with osteolytic lesion in right femora 1 shaft with surrounding sclerosis (Pre op) image

Now for the second patient of male child 11 years old presented with pain around the left ankle and enlarging firm swelling on lateral aspect of left ankle with increasing pain in severity and history was of more than 2 month, by examination swelling was obvious with tenderness over distal third of fibula. Again send for plain X-ray, CT Scan and MRI (figure2) 


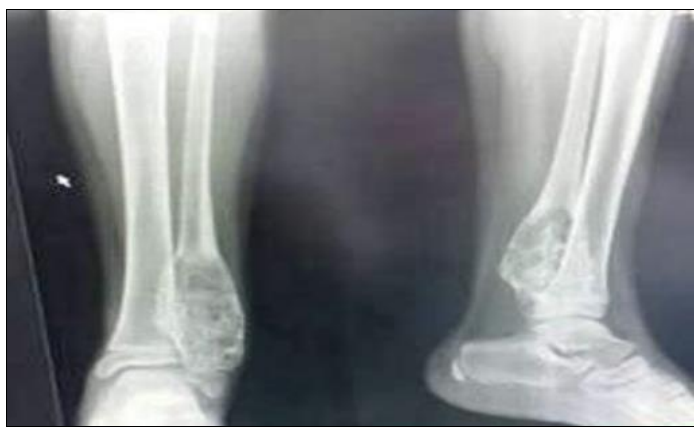

Fig 2: Male of 11years old with cystic lesion of soap bubble appearance, (pre-operative) image

Discussion done with their families each case at their time of presentation which was a 6month apart. Regarding facilities, treatment option, tumor size, experience and rate of recurrence, in both cases decision was made with en bloc resection and the use of fresh non-freezing paternal iliac allograft to close these large bony defect. In preparation for surgery both mothers are not ready for surgery so we choose fathers as a donor site. Screening tests done for fathers regarding any blood disease or blood transmitted disease, no tissue histocompatibility tests are done in both cases, no biopsy pre-op.

Surgery: two adjacent theatre rooms are prepared one for donor and one for recipient and surgery done simultaneously, which facilitate an easy (fresh - nonfreezing) graft transportation between theatres by sterile container and help in measuring the exact graft size needed to be harvested to fit in the defect which done at the time of child surgery during tumor exposure with the assistance of floroscopic screen. Screen floroscopy was also beneficial to avoid any possibility of physeal or normal tissue morbidity and complete tumor exision. No freezing of graft done in our cases.

In the first case (female) the lesion was in right femoral shaft and $8 \mathrm{~cm}$ in size and the allograft size was $9 \mathrm{~cm}$ to be fashioned to fit in the defect after tumor excision and we do internal fixation of femoral shaft prophylactically, by plate and screws $(3$ proximal and 3 distal) and we add 2 screws through the plate to fix the graft, we preserve only $1 / 5$ of lateral cortex of shaft diameter at site of lesion which was clear of tumor and excise $4 / 5$ of shaft diameter by enbloc resection which including the mass, we preserve the length of femur and its rotation during fixation (figure 3).

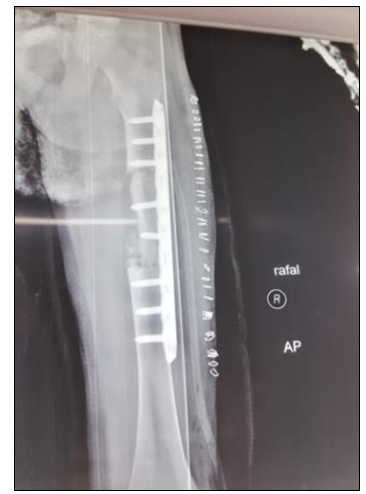

Fig 3: Post-operative image

In second case (11years male) with distal fibular lystic lesion(left leg)the lesion was $9 \mathrm{~cm}$,abute the physis, we do care full sub-periosteal dissection to preserve the syndesmotic ligaments of distal tibiofibular joint (where we suture the periosteum over the graft lastly) and try not to injure the physical line which abuted by the lesion. The graft was $10 \mathrm{~cm}$ in diameter and because of iliac crest graft curved shape we made it in 2 pieces and we fix the graft pieces with fibula by intra medullary k- wire through the lateral malleolus (figure $4 a, b$ ). In this case we do full pop (plaster of paris) cast high below knee after wound closure.

Fathers surgery done as motioned before simultaneously with their sons and graft harvested from iliac crest area (anterior) and cortico-canclleous strut graft with chips of cancellous bone are taken in appropriate size according to per op measurement, the whole harvested graft material was washed out with a normal Saline and then transmitted with sterile container to the adjacent room, the graft was fashioned to fit in the defect and fixed as mentioned for each case. And the chips of cancellous bone are layed out at distal and proximal ends of defect over the graft. Now, washing out secondly done by normal saline for the graft inside the defect after fixation before closure of surgery site in both recipients. These two times of washing processes were to decrease the bone marrow material that was stick with the harvested donor grafts.

Both lesions send for histopathological study which reveal osteoblastoma in female case and primary aneurysmal bone cyst in male one.
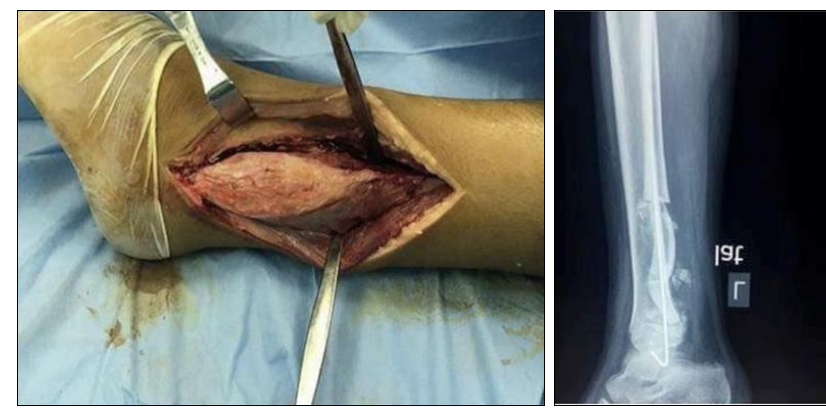

Fig 4: (4a) per op veiw, Figure (4b) post-operative image

\section{Follow up}

- For both cases removal of stitches at two weeks and serial $\mathrm{x}$-ray films follow up for assessment of bone healing which done monthly till healing.

- pop and k- wire are removed in 3 month post - op and start partial weight bearing and then full weight bearing permitted in complete healing evident in radiological film where callus and graft incorporation was complete at 5 month period (figure 5)

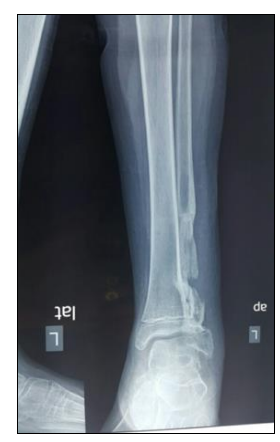

Fig 5: 5 month post op

- In female child complete healing was in 6month by radiological film where callus and graft incorporation was evident. While full weight bearing start earlier because of rigid internal fixation (figure 6). 


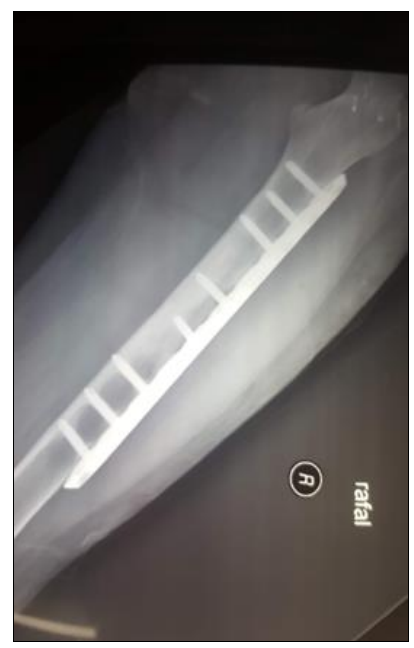

Fig 6: 6 month post-operative day

During follow up period for both no any sign of local nor systemic rejection (Clinically and radiologically). And no significant sign of bone resorption, nor
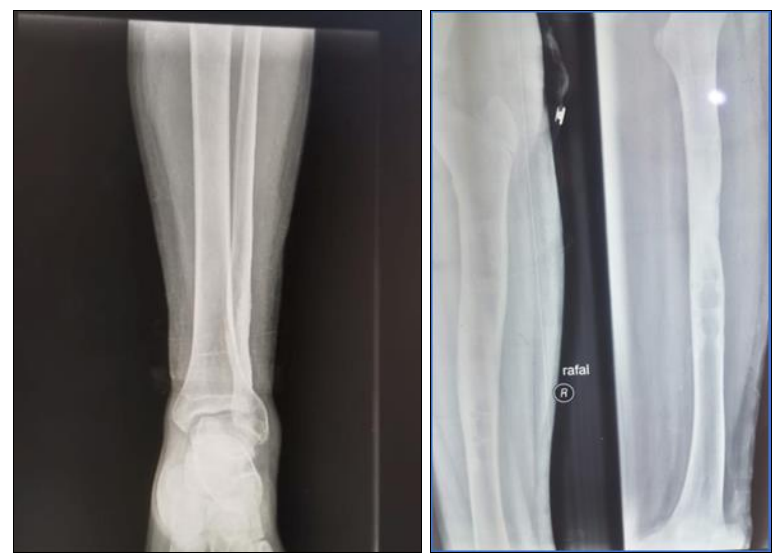

Fig 7, 8: 18 month post operation

Complications are reported (fracture, delayed union or infection), our follow up was continue for 2 years and no any sign for local recurrence was seen. (Figure 7, 8).

\section{Discussion}

Large bone defect in children especially after bone tumor excision is a challenge subject in our orthopedic practice (growing age, small bong mass), so reconstruction choices are limited and size of defect is another challenge regarding facilities and experience in our center.

Bone banks are not available and highly expensive in our country so not included here.

Fresh bone grafts and of course the best are the autogenous, in our cases children had a large defects $(8 \mathrm{~cm}$ and $9 \mathrm{~cm})$ autogenous grafts are not possible because the usual donor site in children do not provide graft large enough to bridge such large defects, the possibility of injury aphysis and autogenous grafts require too long surgery and two sites of operations which carry more morbidity ${ }^{[28]}$. The free vascularized grafts which are highly expensive, need highly skilled centers in microvascular surgery, long time of operation and its not without morbidity of donor site, so not included here. So lastly we go for a cheap, available in good quantity, need no much facilities and have low morbidity for donor sites which is the allograft (fresh - non vascularized) and such graft are usually taken from parent to their children $[21,26,28]$. Multivariate analysis revealed that parental donor type was the only factor significantly associated with overall survival ${ }^{[34]}$.

Regarding rejection of such grafts and acceptance both Fresh and frozen allogeneic bone elicit both acellular and humeral immune response, this response include the development of enhancing factors which block detectable immunity and probably protect the graft from rejection. There seems to be no evidence of alteration in immunogenicity by freezing the graft. the importance of these observation lies in the potential technique of employing fresh viable allograft prior freezing and tissue matching for HLA transplantation antigen should not be necessary ${ }^{[25]}$. So this phenomenon of blocking are defined as the inhibition of transplantation immunity by the formation of serum blocking factor ${ }^{[25]}$ so we don't use freezing for graft nor tissue matching prior surgery in our study.

The most immunogenic element of bone is the marrow, the marrow is resorbed very slowly by host tissue (which contained within cancellous and cortical bone interslices),therefor exposure of marrow (donor antigen) to host immunocompetent cells occur over extended period allow balance between release of antigen and formation of antibody ${ }^{[25]}$.

Furthermore rinsing trabecular allograft may enhance graft incorporation by washing out immunogenic factor present in blood, marrow and fat ${ }^{[22,23,30]}$, we do washing out of our grafts twicely pre and post application of graft in the defect.

The use of fibular or cortical allograft are mention in literatures $[29,21,26,31,32,33]$ but we found no one mention the use of combined cortico cancellous and cancellous fresh allograft ${ }^{[22,24}$ 28, 29].

\section{Cancellous and cortical graft has 3 differences}

a. Cancellous one are revascularized more rapidly and completely than cortical

b. Creeping substitution of Cancellous bone involve initially bone formation phase followed by resorption phase where as cortical one had reverse creeping process.

c. Cancellous graft tend to repair completely with time, so cancellous strengthed first where as cortical are weakened.

Cortical porosity and repair is one of the most cause for graft fracture, delayed or nonunion especially in large graft ${ }^{[29]}$. So we use Cancellous and cortico - Cancellous graft type in our study to report or study their beneficial use in such cases according to the above mention criteria (a, b, c) and what previously discussed in ${ }^{[22,23,30]}$ regarding their antigenicity behavior.

For sites of donating the graft which used in our study was the iliac graft (anterior one) when the iliac graft is the most frequent site if we need large cortico - Cancellous and Cancellous graft combined or non-combined ${ }^{[27,28,29]}$ also in iliac crest graft there is no significant residual disability, no damage to tendinous or ligamentous structures which prevent gait disturbance ${ }^{[29]}$, while the entire $2 / 3$ of proximal fibula may be removed without donor side disability however patient will have complain and mild muscular weakness ${ }^{[16,27,28]}$.

\section{Result}

Our result in this study was excellent regarding the more than expected time of healing (5 month in fibula and6 month in femur) without any complication in such big grafted bony mass (graft fracture, delayed or nonunion) in both cases and this healing was evident by the complete bone incorporation, early callus formation and no any significant bone porosity or resorbtion in the early follow up period, so we do not need for any medication to enhance healing and start early weight 
bearing, also no any disability nor morbidity for donor or recipient follow this massive graft in a big defect of long bone in children. The surgery time was fair enough for the children because two surgeries done in two theaters with two teams in the same time which decrease morbidity. Use of internal fixation was significant in holding graft till healing and encourage early mobilization of patient.

\section{Conclusion}

paternal fresh allograft are good available resources of graft for our children in these large defects cases, which cheap, need no special facilities, no tissue matching pre op nor freezing and the parents are happy to help their children. In our study using of combined Cortico-cancellous and cancellous fresh allow graft we think play a big role in our result regarding rapid bony incorporation, healing and no complication, so we encourage the using of such graft type in similar cases of bony defects and the need for more studies in larger number of patients. Big expanding benign bony lesions in children need aggressive en bloc resection surgery to decrease recurrence rate and avoiding revision surgery for child, of course side by side with careful planning, facilities and experience.

\section{References}

1. Limaiem F, Byerly DW, Singh R. Osteoblastoma - stat pearls - NCBI bookshelf. treausre island (FL): stat pearls publishing 2021. In state pearls \{internet\}. https//www.ncbi.nlm.nih.gov

2. Osteoblastoma - Orth info - AAOS http://orthoinfo. Aaos. Org. osteoblastoma.

3. Wheeless text book of Orthopedics Osteoblastoma http://www. Wheeless online.com/ bone / Osteoblastoma.

4. Gurbuz DM. Ulusoy haseki hospital. Published in 20-112006. Osteoblastoma of the femur /eurorad. http://www.eurorad.org

5. Terry Canale S. Campbells operative orthopedic; ninth editon, volume one, copyinynit 1998, 709.

6. Fred Ortmann, Omohodion Binitie, Francisco talavera. Osteoblastoma: practice essenssial: anatomy. Pathophysiologyy and Etioloyg, Epidemiology and prognosis.

http://emedicine,medscape.com/article/1257927-overview up dated 2020.

7. Fred Ortmann, omohdion Binitie, Francisco talavera Osteoblastoma; Treatment and Mangement updated 2020. https://emedicine,Medscape.com/article1257927- treatment.

8. Cerase A, Priolo F. Skeletal Benign bone- forming lesion. Eur J Radiol 1998;1:S91-7. http://pubmed,ncbi,nlm,nih,gov.

9. Osteoblastoma- pathology - orthobullets http://wwworthobullets.com/pathology/8013/Osteoblastoma.

10. Tedesco N, Binitie O, Eastwood B, Talavera F. Aneurysmel bone cyst treatment and management. Updated Apr 20, 2021.

http://emedicine.Medscaps.com/article/1254784-treatment

11. Rapp Timothy B, Ward MD, James P MD, Alaia Michael J MD. Aneurysmal bone cyst. Journal of the American academy of orthopedic surgeons 2012;20(4):233-241. http://journal/www.com/jaaos/Abstract/2012/04000/aneurys mal- bone-cyst.

12. Howard Park Y, Sarak Yang et al. Current management of aneurysmal bone cysts-NCBI. Current review Musculo skelet Med 2016;9(4):435-444. https://www.ncbi.nlm.nih.gov/pmc/articles.

13. Ziyad Mohaidat M, Salah R, Al-gharaibeh Osama N,
Aljarahih Murad T, Nusairat, Al-omari A. Challenges in the diagnosis and treatment of Aneurysmel bone cyst in pateint with unusual features 2019. Ardich ID 29056. https://www.Hindawi.com/journale/aorth/2019/290567.

14. Devener N, Schulze M, Gosheger G, De vaal M, Deventer N. Primary Aneurysmal Bone Cyst and Its Recent Treatment Options: A Comparative Review of 74 Cases. cancers 2021;13:2362. http://www.mdpi.com/journal/cancers.

15. Henry Mankin J, Farancis J, Hornicek, Eduardo Ortiz-cruz. Jorge villafuerte. Mark C. Gebhardt Aneurysmal bone cyst: Areview of 150 pateints. Journal of clinical oncology 23(27). https://ascopubs.org.

16. Philip B, Fontenot Gesurajang, Bui M, Reed O, Binitie O. Recurrent Aneurysmal Bone Cyst of the Distal Fibula Treated with Denosumab and Curettage 2018. Article ID 1574343. https://emedicine.medscapc.com http://www.Hindawi.com.nebi.nlm.Nih.Gov.

17. Tedesco N, East wood B, Talavera F, Binitie O. Aneurysmal, Bone Cyst: practice Essentials, Anatomy, pathophysiology. Up dated April 20, 2021. https://emedicine,medscape.com/article/1254784-overview.

18. Basarir K, Piskin A, Guclu B, Yildiz Y, Saglik Y. Aneurysmal Bone cyst recurrence in children: overview of 56 patients. J pediatr orthop 2007:27(8):938-43. https://pubmed.ncbi nlm.nih.gov.

19. Aneurysmal Bone Cyst - pathology. Orthobullets. https://www.orthobullets.com/pathology/8039/aneurysmalBone-cyst.

20. Nsari M, Gantam D, Kotwal P. Mother's fibula in son's forearm: use of maternal Bone grafting for aneurysmal Bone cyst not amenable to curettage. Acase report with review of literatures. Sicot - J 2016;2:18. http://www.sicotj.org/article/sicotj.

21. Kadir M, Askari R, Sher baz. Use of fresh parental fibular allograft for recostruction of skeletal defects after limb salvage surgery $2014,64(12,2)$. http://ecommons.aku.edu/Pakistan.

22. Bone grafting-Basic science - orthobullets. https://www.orthobullets.com/basicscience/9011/bonegrafting.

23. Van der Donk S, Weernink T, Buma P, Asperberg P, Sloof TJ, Schreurs BW. Rinsing morselized allografts improves Bone and tissue ingrowth. Clinical orthopedics and related research 2003;408:302-310. https://www.researchgate.net.

24. Burchardt H. The Biology of Bone graft repair. Clinical orthopedics and related research 1983;174:28-42. europepmc.org. https://pubmed.ncbi.nlm.nih.gov.

25. Langer F, Czitrom A, Pritzker KP, Gross AE. The immunogenicity of fresh and frozen allogeneic bone graft.The journal of bone and joint surgery 1975;57(2):216220. https://pubmed.ncbi.nlm.nih.gov.

26. Docquier Pl, Paul L, Mousng M, Cornu O, Delloge C. The use of allografts in pediatric orthopedic surgery. Acta orthop belg 2007;73(s):551-7. https://pubmed.Ncbi.nlm.nih.gov.

27. Nguyen Ngoc Hung. Basic knowledge of Bone Grafting 2012. https://www.Researchgate.net/publication. http://edu.intech open.com

28. S. Terry Canale Campbells operative orthopedic. Ninth edition, volume one copyright 1998, 40-43.

29. Yasar Mohsut Dinal. Bone Graft Types. publish 2018. https://www.Intechopin.com/chapter/62497/

30. Fresh osteochondral Allograft frequently Asked Question. 
http://www.Lifenethealth.org/sites/default/files/files/68-30098. Pdf

31. Ramnarian A, Govender S. Fibular allograft and anterior plating for dislocations / Fractures of the cervical spine. Indian J orthop 2008;42(1):83-86.

https: // www. ncbi.nlm. nih.gov / pmc/ articles/.

32. Yeh KT, Lee RP, Chen IH, Yu TC, Li KL, Peng CH, et al. Fresh frozen cortical strut allograft in two-level anterior cervical corpectomy and fusion. PLOS one 2017;12(8):eo183112.

https://journals.plos.org/plosone/article

33. Devalia KL, Mehta R, Yagnik MG. Use of. Maternal bone grafting for long standing segmental gap non- union in Osteogenesis Imperfecta. A case report with review of literatures. Injury 2005;36(9):1130-1134.

http;//pubmed.ncbi.nlm.nih.gov

34. Tamaki Ichinohe T, Matsuo K, Hamajima N, Hirabayashi N, Dohy H. Japan Society of Hematopoietic Cell Transplantation. Superior survival of blood and marrow stem cell recipients given maternal grafts over recipient given paternal grafts 2001;28(4):375-80.

http://pubmed.ncbi.nlm.nih.gov 